\title{
Research on Performance and Valuation of Enterprises Placarded by Others Based on the Improved Panel Vector Auto-Regression Model
}

\begin{abstract}
Na Luo
Correspondence: Na Luo, School of Banking and Finance, University of International Business and Economics, Beijing, China.
\end{abstract}

Received: February 9, 2018

doi:10.11114/aef.v5i3.3006

\author{
Accepted: March 8, $2018 \quad$ Available online: March 18, 2018 \\ URL: https://doi.org/10.11114/aef.v5i3.3006
}

\begin{abstract}
In recent years, enterprises, which were placarded, have become a heated issue in the secondary market in China. However, there still lack researches about the performance and valuation of those enterprises which were placarded. Therefore, it seems that it is lack of persuasion to use the word "barbarians" to define the enterprises which carry out placard. For the reasons above, this paper makes the use of the improved PVAR model to give an empirical analysis on the performance and valuation of the enterprises placarded, based on the samples between 2011 and 2015. First, this paper divides the whole samples into two subsample groups by the dummy variable, according to the certain point of time whether the enterprise has been placarded. After that, it build two PVAR models combining the performance indicators and the valuation indicators. The results show that the sensitivity of the target enterprise's performance is not as good as its valuation. Second, the two subsample groups are analyzed by the impulse response function. It explains that placard creates an incentive effect for the target enterprise in the short term. Third, by using the variance decomposition, this paper achieves a conclusion that placard reduces the dependence of the target enterprise on the aspects of its valuation, profitability, size and risk. Therefore, placard is a good signal for those target enterprises on the whole, which brings a nice momentum for the enterprises on the valuation, profitability, size and risk in the short term. In the long run, the enterprises will adjust to a stable state based on the short-term changes. From this point of view, "barbarians at the gate" bring the motivation rather than chaos.
\end{abstract}

Keywords: placard, improved PVAR model, GMM estimation, impulse response function, variance decomposition

\section{Introduction}

Placard means an act that a shareholder needs to report to related institutions when he increases shares of one listed company to more than 5\% in the secondary securities market. In recent years, placard has been a heated discussion in domestic capital market. Especially in 2015, insurance companies carried out placard towards listed companies on a massive scale, which caused a lot of attention besides the dramatic up and down in the stock market. After that, the secondary securities market put on a placard upsurge of private funds and retail investors. In fact, placard is not an emerging new term in recent years. Since the share split reform in 2005, placard has become an increasingly active role in the market. There are 230 placard events in the secondary market between 2006 and 2016. However, there are few researches about the target enterprises which are placarded, so it is of great significance to focus on this issue and analyze these enterprises in the secondary market.

The word "barbarians" is usually used to define the enterprises which carry out placard. These enterprises always increase shares of the target companies at the right time, so they behave as the barbarians at the gate. However, it seems too negative to use the word barbarian to define them. On the one hand, they add lots of vitality to the stock market, and on the other hand, the placard effect on the performance and valuation of the target company can not be simply summed up in terms of the purpose of the placard executor.

\subsection{Foreign Literatures}

In foreign research, Kumar(1985) studied more than 2000 placard cases from 1960 to 1976 by using linear regression, which found that most of the target companies have a declined performance. Gugler, Muelle and Yurtoglu(2003) focused on 429 overseas M\&A samples from America, Japan and Britain between 1981 and 1998, and found the total profits of large enterprises had increased significantly after M\&A. Love and Zicchino(2006) established PVAR models to analyze the impact of corporate financial situation on its investment behavior in 36 countries, in which they divided 
the samples into two subsample groups according to the level of financial development. Aziz N.Berdiev and James W.Saunoris(2016) explored the dynamic relationship between financial development and shadow economy in 161 countries by impulse response function of panel vector auto-regression model, which found financial development has weakened the scale of shadow economy. Rekha Rao-Nicholson, Julie Salaber and Tuan Hiep Cao(2016) analyzed the financial data of target companies after its M\&A in ASEAN countries from 2001 to 2012, achieving that operation achievement tended to decline after 3-years adjustment, and these companies seemed to perform better during financial crisis than any other period of time. After that, they concluded the relative goals of company, transnational nature of the transaction, cash reserves of the acquirers, and friendliness of the transaction are the important determinants of the business performance after M\&A, during the crisis.

\subsection{Domestic Literatures}

On the basis of dynamic panel model, Lei Hui, Shao Huawei, Li Ai(2010) found the M\&A of listed companies in low carbon industry is beneficial to increase the labor demand of the company. The model in this paper introduced dummy variable to measure the occurrence of M\&A during the fiscal year, aiming at avoiding the inconsistency of individual data during the investigation. In the research conducted by Sun Xin(2011), it concluded the increase of share proportion of major shareholders would bring a positive impact on the stock price of the listed company. By studying the stock events, Wu Jianan(2012) analyzed the short-term performance of M\&A of Chinese listed pharmaceutical companies between 2005 and 2008. Then he came up with a nonparametric model of panel data, which was used to analyze the long-term performance of $\mathrm{M} \& \mathrm{~A}$ in this kind of companies. It turned out that the short-term performance of listed pharmaceutical companies had been improved after M\&A, while in the middle and long term, the performance had not improved but overall efficiency and technical efficiency had increased. He Jing, Xu Longbing(2012) found the performance of listed companies placarded by others had improved and the share of product market had enhanced, with the industrial capital infiltrating into the financial capital.

By analyzing the stock events, Yang Yang(2013) came to a conclusion that senior executives of listed companies increased their shares based on the market for great majority, rather than the corporate performance and development ability. Zuo Wenwen(2013) used a mixed section model of panel data, including unit root test and descriptive statistics, to summarize the relationship between executive payment and corporate performance, enterprise scale, board size, proportion of independent directors, proportion of state-owned shares and region respectively. Pang Jiang(2014) focused on the listed companies with changes in the proportion of shares in 2009, with the result that the changes of shares of major shareholders were time-related, based on the performance of different stocks. Meanwhile, on the basis of principal component analysis, it turned out that if major shareholders increased their shares, the company would meet a decline in performance, and vice versa.

Later in the research conducted by Lv Pin(2014), event study, paired sample T test and multiple regression were used to analyze the placard events in A stock market during 2008 and 2013. The results suggested that placard made a decline in target companies' performance, and the impact of company growth, solvency and size on placard was unobvious, while the ownership structure and Tobin Q had a significant impact on placard. Chen Yongxue(2016) summarized two representative placard cases about Qinhuangdao Maoye and Lingshi Investment, with M\&A and strategic long-term investment motive respectively. By comparing different indexes, the paper proved that two kinds of motives can both optimize the resource and structure of the target companies, and improve their value. On the basis of endogenous effect, Luo Chengde(2016) used the fixed effect panel data simultaneous equations to analyze the relationship between payment gap and business performance, which took research and development strength into consideration. After acquiring the related data of listed companies from 2012 to 2014, he showed the impact of payment gap and research and development strength on the corporate performance.

\subsection{Literature Review}

The achievements of foreign researches and domestic researches share few resemblances in results, and most of domestic researches concentrated on principal component analysis and paired sample $\mathrm{T}$ test. It seems that there are lack of researches about placard effect on corporate performance and valuation by using PVAR model, and previous studies show no rigorous sample selection and distinction, which may bring a significant impact on the results. Therefore, based on the advantages of PVAR model, the paper introduces dummy variable to establish an improved PVAR model, using financial indexes and valuation indexes to analyze the change in corporate performance and valuation. With the results of the model, we can come to a conclusion whether the barbarians at the door bring motivation for the target company or not. In this way, we can make full use of the strengths of quantitative finance and corporate finance to achieving a more convincing conclusion. As for major shareholders and investors, the results can assist them to identify valuable investment and future development pattern of target companies. For those target companies which have been placarded, they can specify the direction for future corporate governance and development based on the results.

The paper establishes a system that examines the changes in performance and valuation of listed companies which have 
been placarded. For its strong applicability, the system can be used not only in the field of corporate finance, but also in different fields at home and abroad. By changing the variables in the model and the lagged order, we can reach different research purposes, which provides a helpful tool for the study of panel data.

\section{Selection of the Sample and Indexes}

\subsection{Selection of the Sample}

The paper deals with the problem of corporate performance and valuation of the listed companies which have been placarded. However, it may be a long-term process to make the impact of placard on the target company's performance come into effect. If we just use the data of one season to study the issue, the model wouldn't perform well by the selected samples. Therefore, the paper eliminate those listed companies placarded in 2016 for the first time, in order to make the data period long enough. The data we used in this paper comes from WIND data terminal. With a full consideration of various samples, this paper concentrates on studying the hypostatic companies in the industrial capital.

In 2005, the share split reform came into effect, so I regard the year 2005 as starting point of our research. Therefore, the target companies which have been placarded in Chinese secondary securities market from 2006 to 2015 are summarized in this paper. Once the same company was repeatedly placarded during the research period, the first announcement time was regarded as the research time point, which ensures the research time would not overlap for a single company.

With the need of this research, the paper first selects samples based on the following standards.

Firstly, the cases that non-major shareholders and non-senior executives increase their shares through special trade such as repo transaction are excluded from the samples.

Secondly, the placard cases that do not happen in the secondary market are excluded from the samples. For example, if the transaction is carried out by free transfer or judicial transfer, it will not be included in the target samples.

Thirdly, after the first placard announcement, if the stock appears suspended for a long time or the stock price is influenced by some major matters, such as high proportion of ex-right, affiliate transaction, asset reorganization and so on, the corresponding company will be excluded from the samples. Since long-time suspension or major matters will affect the corporate performance and valuation more or less, the effectiveness of the conclusion will be unconvincing if these types of companies are included in the samples.

Fourthly, financial listed companies are excluded from the samples, for the reason that the operation achievements share great differences between financial listed companies and other listed companies.

Fifthly, those listed companies which have been marked ST or "ST are excluded from the samples. Considering these companies may avoid delisting through selling fixed assets or creating financial fraud under the circumstance of continuous losses, it is not worth studying this kind of profit arising from non-main business.

Sixthly, the companies with no transaction data within 15 days after first placard announcement are excluded from the samples.

According to the standards above, 173 listed companies are summarized as the samples between 2006 and 2015. The number of placard cases of each year is shown in Table 1.

Table 1. The number of placard cases in Chinese secondary securities market between 2006 and 2015

\begin{tabular}{cc}
\hline Year & Number \\
\hline 2006 & 1 \\
2007 & 5 \\
2008 & 33 \\
2009 & 9 \\
2010 & 9 \\
2011 & 26 \\
2012 & 33 \\
2013 & 23 \\
2014 & 23 \\
2015 & 68 \\
Total & 173 \\
\hline
\end{tabular}

According to the and number of placard cases of each year since 2006, in this paper, the companies which meet its first placard from January 1, 2011, to December 31, 2015, are selected as the final samples, so as to keep the continuity of the sample interval and the feasibility of the research.

The corporate performance and valuation of sample companies may have a lag in response to placard. Therefore, based on the availability of data, this paper selects the financial data of the target companies from the second quarter of 2010 
to the third quarter of 2016 as the sample data. Then the companies with abnormal financial data or missing data are excluded from the sample. At last, I select 135 companies as the final sample. The results of sample selection are show in Table 2.

Table 2. The number of sample companies in each year between 2011 and 2015

\subsection{Sample Distribution Statistic}

\begin{tabular}{cc}
\hline Year & Number \\
\hline 2011 & 19 \\
2012 & 25 \\
2013 & 17 \\
2014 & 19 \\
2015 & 55 \\
Total & 173 \\
\hline
\end{tabular}

The sample companies can be classified into different groups as below, based on the stock exchange and the industry.

Table 3. Sample distribution based on the stock exchange

\begin{tabular}{ccc}
\hline Stock exchange & Number & Proportion \\
\hline Shanghai Stock Exchange & 65 & $48.15 \%$ \\
Shenzhen Stock Exchange & 70 & $51.85 \%$ \\
Total & 135 & $100 \%$ \\
\hline
\end{tabular}

Table 4. Sample distribution based on the industry

\begin{tabular}{ccc}
\hline Industry & Number & Proportion \\
\hline Material & 23 & $17.04 \%$ \\
Real estate & 15 & $11.11 \%$ \\
Utility & 11 & $8.15 \%$ \\
Retail & 9 & $6.67 \%$ \\
Media & 11 & $8.15 \%$ \\
Technical hardware and equipment & 4 & $2.96 \%$ \\
Energy & 9 & $6.67 \%$ \\
Durable consumer goods and clothing & 2 & $1.48 \%$ \\
Automotive and automotive components & 6 & $4.44 \%$ \\
Software and services & 2 & $1.48 \%$ \\
Business and professional services & 2 & $1.48 \%$ \\
Food, drink and tobacco & 7 & $5.19 \%$ \\
Retail of food and main products & 3 & $2.22 \%$ \\
Consumer service & 2 & $1.48 \%$ \\
Medical and healthcare & 2 & $1.48 \%$ \\
equipment and services & 3 & $2.22 \%$ \\
Transport & 6 & $4.44 \%$ \\
Pharmaceutical, biotechnology & 18 & $13.33 \%$ \\
and life science & 135 & $100 \%$ \\
Capital goods & 53 & \\
Total & &
\end{tabular}

As the results presented above, there are 65 companies listed in Shanghai Stock Exchange and 70 companies listed in Shenzhen Stock Exchange, which indicates that the samples distributes averagely. Although the number of samples varies across industries, the samples are widely distributed in different industries, which effectively enhances the representativeness and universality of the conclusion in this paper.

\subsection{Data Indexes}

\subsubsection{Company Performance Indexes}

According to the characteristic of listed companies, the paper measures the company performance from profitability, company size and company risk, and then establish an evaluation system of company performance by selecting appropriate indexes from these three aspects respectively. The results to these indexes are shown in Table 5.

Table 5. Company performance indexes

\begin{tabular}{ccc}
\hline First-level indexes & Second-level indexes & Representative symbol \\
\hline \multirow{2}{*}{ Profitability } & Earnings per share & EPS \\
& Profit margin on net assets & ROE \\
Company size & Main business income & MI \\
Company risk & Total assets & TA \\
\hline
\end{tabular}




\subsubsection{Company Valuation Indexes}

In this paper, the market value of company is used as an index of company valuation, which refers to the total value of the stock issued by a listed company based on the market price. In order not to be influenced by the dividend distribution in the sample, the paper first narrows the gap of previous ex-right based on the present market value of the company.

\section{Empirical Analysis}

\subsection{Variable Analysis}

\subsubsection{Variable Description}

The paper establishes an improved panel-data vector auto-regression model, namely PVAR model, to conduct an empirical analysis on the performance and valuation of the companies which have been placarded. In order to solve the problem of individual non-equilibrium in the sample, the PVAR model introduces a dummy variable to analyze the placard effect. If the company is placarded at a certain point of time, then the dummy variable equals 1 . Otherwise, the dummy variable equals 0 . In order to linearize the developing trend of the variable and reduce the potential heteroscedasticity of the panel data, the paper does logarithm treatment on the quantitative data. The variables used in this paper are shown in Table 6.

Table 6. Variable description

\begin{tabular}{ll}
\hline Variable & \multicolumn{1}{c}{ Description } \\
\hline $\ln M V_{i t}$ & Natural logarithm of market value of company $i$ at time $t$ \\
$E P S_{i t}$ & Earnings per share of company $i$ at time $t$ \\
$\ln T A_{i t}$ & Natural logarithm of total assets of company $i$ at time $t$ \\
$D A R_{i t}$ & Debt to asset ratio of company $i$ at time $t$ \\
$R O E_{i t}$ & Profit margin on net assets of company $i$ at time $t$ \\
$\ln M I_{i t}$ & Natural logarithm of main business income of company $i$ at time $t$ \\
$c_{i t}$ & Dummy variable \\
\hline
\end{tabular}

\subsubsection{Data Analysis}

The final sample in this paper contains 135 companies. In order to overcome the influence of outliers and control the loss of the sample data after processing, trim truncation is performed at $1 \%$ and $99 \%$ quantiles by Stata11.0. The statistic results of the final sample are shown in Table 7 and Table 8.

Table 7. Statistical characteristics of variables of Panel A

\begin{tabular}{cccccccc}
\hline \multicolumn{7}{c}{ Panel A: } & After placard \\
\hline Variable & Mean & $\begin{array}{c}\text { Standard } \\
\text { deviation }\end{array}$ & Minimum & $\begin{array}{c}\text { Upper } \\
\text { quartile }\end{array}$ & Median & $\begin{array}{c}\text { Lower } \\
\text { quartiles }\end{array}$ & Maximum \\
lnMV & 22.59 & 0.84 & 20.81 & 22.00 & 22.51 & 23.10 & 25.22 \\
EPS & 0.28 & 0.36 & -0.71 & 0.06 & 0.22 & 0.43 & 1.60 \\
lnTA & 22.33 & 1.23 & 19.40 & 21.48 & 22.27 & 23.19 & 25.75 \\
DAR & 0.50 & 0.19 & 0.07 & 0.36 & 0.51 & 0.65 & 0.90 \\
ROE & 0.05 & 0.08 & -0.49 & 0.02 & 0.06 & 0.10 & 0.25 \\
lnMI & 20.88 & 1.60 & 16.12 & 19.83 & 20.93 & 22.02 & 24.21 \\
\hline
\end{tabular}

Table 8. Statistical characteristics of variables of Panel B

\begin{tabular}{cccccccc}
\hline \multicolumn{7}{c}{ Panel B: Before placard } \\
\hline Variable & Mean & $\begin{array}{c}\text { Standard } \\
\text { deviation }\end{array}$ & Minimum & $\begin{array}{c}\text { Upper } \\
\text { quartile }\end{array}$ & Median & Lower & quartiles \\
lnMV & 22.20 & 0.84 & 20.74 & 21.59 & 22.07 & 22.73 & 25.21 \\
EPS & 0.28 & 0.31 & -0.72 & 0.09 & 0.22 & 0.44 & 1.59 \\
lnTA & 21.91 & 1.11 & 19.29 & 21.07 & 21.84 & 22.74 & 25.40 \\
DAR & 0.50 & 0.18 & 0.07 & 0.36 & 0.53 & 0.64 & 0.90 \\
ROE & 0.06 & 0.09 & -0.51 & 0.03 & 0.07 & 0.11 & 0.25 \\
lnMI & 20.60 & 1.56 & 16.12 & 19.62 & 20.58 & 21.69 & 24.22 \\
\hline
\end{tabular}

The statistic indicators of six variables all become larger when using the after-placard data. To a certain extent, it reflects placard has optimized the profitability of the company, enlarged the company size, and increased the company risk at the same time. However, it can only explain the overall situation of the company for a period of time before and after placard, which fails to represent the response to placard in each period.

\subsection{Model Establishment}

This paper uses a panel-data vector auto-regression method to study the placard effect on corporate performance and 
valuation of the target companies. This kind of method combines the traditional VAR approach, which treats all the variables in the system as endogenous, with the panel-data approach, which can more truly reflect the relationship between the various variables and allow for unobserved individual heterogeneity and time effect. By combining the advantages of time series model, section data model and panel data model, it provides an effective method for analyzing the dynamic response $f$ target variables when receiving impact.

The PVAR model, first put forward by Holtz-Eakin in 1988 and later developed by experts and scholars such as Kao, Joakin Westerlund and so on, has become an ideal model for panel data. $T$ stands for the length of the time series, and $n$ stands for the length of the hysteresis term. In the PVAR model, as long as the condition $T \geq n+3$ is satisfied, the unknown parameters can be estimated through the equation. In addition, the parameters of hysteresis term can be estimated under steady state when the condition $T \geq 2 n+2$ is satisfied.

The PVAR model is mainly composed of the following three parts. The first is to determine the lagged order and complete GMM estimation, with the purpose of reflecting the regression relationship between variables. The second is to estimate the impulse response function and draw the function image, aiming at observing the response of each target variable after receiving impact. The third is to complete the variance decomposition of prediction error, in order to measure the change of the error influenced by the variable itself or other variables in the prediction.

The PVAR model first removes the individual effect within the sample by forward difference method and eliminates the time effect on the basis of the mean value in the group. After that, it carries out the regression calculation and test. Traditional PVAR model has some limitations in data processing, calculation and so on. These limitations are mainly embodied in the following aspects. Firstly, the traditional model focuses on the name of cross-sectional variable, which limits the flexibility of the variable. Secondly, the mean effect within the group is not eliminated in the traditional model. Thirdly, impulse response function and variance decomposition can not be flexibly adjusted, for the period in the model is restricted. Fourthly, the traditional model is limited by the first-order lag. On the basis of the limitations of the traditional model, the improved PVAR model used in this paper can not only eliminate the restriction of variables, the individual effect and the time effect of the sample, but also improve the selection of the lagged order, impulse response function and variance decomposition, which makes the model more substantial.

\subsubsection{Theoretical Model Setting}

By using the indexes of profitability, size, risk and valuation, the paper establishes an improved PVAR model, and uses Stata11.0 to perform it. A first-order VAR model is specified as follows.

$$
Z_{i t}=\Gamma_{0}+\sum_{j=1}^{p} \Gamma_{j} Z_{i, t-j}+f_{i}+d_{i t}+e_{t}
$$

Where $Z_{i t}$ is a six-variable vector, containing all endogenous variables in the model system, namely

$\left\{\ln M V_{i t}, E P S_{i t}, \ln T A_{i t}, D A R_{i t}, R O E_{i t}, \ln M I_{i t}\right\} . f_{i}$ stands for individual heterogeneity, used to measure individual

effect, and $d_{i t}$ is a time dummy variable, used to measure time effect.

The order of variables in the vector is arranged based on the assumption that the value and earnings are affected first, and then the capital changes. When the new capital is used for new investment, it will affect the company income. The assumption forms on the basis of the following reasons. First of all, the most obvious impact of placard on company is the total market value in the short term, for the reason that the total market value is influenced by the stock price and the number of stocks, and placard often brings about a change in the capital stock. Second, because earnings per share are equal to the net profit of company divided by the number of stocks, the change in capital stock will affect the earnings per share. Third, the items related to the company's assets may change because of placard, which leads in the change of investment. However, the company often needs some time to fully operationalize the new capital, so the returns may have some delay. Last but not least, the increase in investment may lead to changes in the income of the company. Therefore, the variables in the model not only represent the company's financial information, but also indicate the potential relationship within them.

One of the limitations we need to impose when applying panel data to a VAR model is that each cross-sectional unit is the same, but it is quite impractical in practice. Therefore, by introducing a fixed effect that allows for individual heterogeneity in the variables, the model can solve the limitation above well. Because the fixed effect is related to the lag of variables, considering the mean difference method usually produces the a deviation coefficient when eliminating the fixed effect, the paper removes the individual effect within the sample by forward difference method, which is called Helmert process. It removes only the forward average value, which is the average value of future observations available for each business year. In this way, we can preserve the orthogonality between transformed and lagged 
variables, and then we can use the lagged variable estimated by GMM as the tool variable to obtain the corresponding regression coefficients.

\subsubsection{Estimated Results}

By introducing the dummy variable, the model is divided into PVAR-A model and PVAR-B model. The former one uses the data of the company after placard, and the latter one adopts the data before the company is placarded.

When performing GMM estimation, we need to eliminate the individual effect and time effect in PVAR model. This paper removes the individual effect by forward difference method and eliminate the time effect by in-group mean difference method on the cross section. On the basis of AIC, BIC and HQIC criteria, the most proper lag order of PVAR-A model and PVAR-B is 2. The estimated results of PVAR-A(2) and PVAR-B(2) are shown in Table 9 and Table 10.

Table 9. Results of PVAR-A(2)

\begin{tabular}{|c|c|c|c|c|c|}
\hline \multirow{2}{*}{\multicolumn{3}{|c|}{$\begin{array}{l}\text { PVAR-A: PVAR model after placard } \\
\text { Response of: } h \ln M V\end{array}$}} & \multirow{2}{*}{\multicolumn{3}{|c|}{ Response of: $h \_E P S$}} \\
\hline & & & & & \\
\hline \multicolumn{3}{|c|}{ Response to $\bar{C}$ oefficients $t$ statistics } & \multicolumn{3}{|c|}{$\begin{array}{l}\text { Response of: h_EPS } \\
\text { Response to Coefficients } \quad \text { t statistics }\end{array}$} \\
\hline \multicolumn{6}{|l|}{ L.h_lnMV } \\
\hline & 0.077 & 0.38 & L.h_EPS & $0.601 * * *$ & 5.61 \\
\hline L.h_lnTA & 0.044 & 0.24 & L.h_lnTA & 0.113 & 1.15 \\
\hline L.h_DAR & 0.983 & 1.16 & L.h_DAR & -0.604 & -1.27 \\
\hline L.h_ROE & -0.978 & -1.34 & L.h_ROE & $2.394 * * *$ & 5.67 \\
\hline L.h_lnMI & -0.007 & -0.24 & L.h_lnMI & -0.011 & -1.09 \\
\hline L2.h_lnMV & $0.295 * * *$ & 5.95 & L2.h__lnMV & -0.013 & -0.66 \\
\hline L2.h_EPS & -0.103 & -1.57 & L2.h_EPS & 0.011 & 0.3 \\
\hline L2.h_lnTA & $-0.128 * *$ & -2.20 & L2.h_lnTA & $-0.057 *$ & -1.77 \\
\hline L2.h_DAR & $0.419 *$ & 1.91 & L2.h_DAR & 0.053 & 0.47 \\
\hline L2.h_ROE & -0.031 & -0.05 & L2.h_ROE & $-0.881 * *$ & -2.55 \\
\hline L2.h_lnMI & 0.018 & 0.94 & L2.h_lnMI & $-0.013^{*}$ & -1.71 \\
\hline \multicolumn{6}{|c|}{ Response of: $\quad h \_\ln T A$} \\
\hline Response to & Coefficients & $\mathrm{t}$ statistics & Response to & Coefficients & $\mathrm{t}$ statistics \\
\hline \multicolumn{6}{|c|}{$\begin{array}{lccccc}\text { L.h_lnMV } & 0.01 & 0.23 & \text { L.h_lnMV } & -0.003 & -0.20\end{array}$} \\
\hline L.h_EPS & 0.083 & 0.94 & L.h_EPS & 0.052 & 1.26 \\
\hline \multicolumn{6}{|l|}{ L.h $\ln \mathrm{TA}$} \\
\hline \multicolumn{6}{|l|}{ L.h_DAR } \\
\hline \multicolumn{6}{|l|}{ L.h_ROE } \\
\hline \multicolumn{6}{|l|}{ L.h_lnMI } \\
\hline \multicolumn{6}{|l|}{ L2.h_lnMV } \\
\hline \multicolumn{6}{|l|}{ L2.h_EPS } \\
\hline L2.h_lnTA & 0.006 & 0.18 & L2.h_lnTA & 0.025 & 1.45 \\
\hline $\begin{array}{l}\text { L2.h_In IA } \\
\text { L2.h DAR }\end{array}$ & 0.176 & 1.25 & L2.h_DAR & 0.08 & 1.14 \\
\hline L2.n_DAK & -0.164 & -0.58 & L2.h_ROE & -0.154 & -1.13 \\
\hline \multicolumn{6}{|c|}{ L2.h_lnMI $\quad 0.01$} \\
\hline Response of: & h_ROE & & Response of: & h_lnMI & \\
\hline Response to & Coefficients & $\mathrm{t}$ statistics & Response to & Coefficients & $\mathrm{t}$ statistics \\
\hline L.h_lnMV & -0.002 & -0.18 & L.h_lnMV & -0.146 & -0.99 \\
\hline L.h_EPS & 0.027 & 0.8 & L.h_EPS & -0.696 & -1.53 \\
\hline L.h_lnTA & -0.007 & -0.20 & L.h_lnTA & 0.202 & 0.51 \\
\hline L.h_DAR & 0.145 & 0.8 & L.h_DAR & -0.131 & -0.07 \\
\hline L.h_ROE & $0.716 * * *$ & 3.68 & L.h_ROE & 0.162 & 0.1 \\
\hline L.h_lnMI & 0.002 & 0.46 & L.h_lnMI & $-0.152 * *$ & -2.38 \\
\hline L2.h_lnMV & -0.011 & -1.62 & L2.h_lnMV & $0.348 * * *$ & 3.26 \\
\hline L2.h_EPS & $-0.024 *$ & -1.86 & L2.h_EPS & -0.098 & -0.70 \\
\hline L2.h_lnTA & 0.012 & 1.54 & L2.h_lnTA & $0.513 * * *$ & 3.18 \\
\hline L2.h_DAR & 0.03 & 0.97 & L2.h_DAR & 0.093 & 0.21 \\
\hline L2.h_ROE & -0.12 & -1.30 & L2.h_ROE & 1.886 & 1.58 \\
\hline L2.h_lnMI & 0.001 & 0.23 & L2.h_lnMI & $-0.341 * * *$ & -6.72 \\
\hline $\mathrm{N}$ & 987 & & & & \\
\hline AIC & -7.476 & & & & \\
\hline BIC & -3.102 & & & & \\
\hline HQIC & -5.812 & & & & \\
\hline$* p<0.1$ & $05, * * * 1$ & & & & \\
\hline
\end{tabular}


As can be seen from Table 9, the market value of a company is not only positively affected by its value of the first-order lag and the second-order lag, but also significantly influenced by the total assets and debt to asset ratio of the second-order lag. The impact from the total assets is negative, while the influence from debt to asset ratio is positive. To a certain extent, it indicates that the larger the total assets of the previous two periods or the lower the debt to asset ratio of previous two periods, the lower the current market value. As for other variables, the results above also show that they will be significantly affected to various degrees by the variable itself or other variables.

Table 10. Results of PVAR-B(2)

\begin{tabular}{|c|c|c|c|c|c|}
\hline \multicolumn{6}{|c|}{ PVAR-B: PVAR model before placard } \\
\hline \multicolumn{3}{|c|}{ Response of: h_lnMV } & \multicolumn{3}{|c|}{ Response of: h_EPS } \\
\hline Response to & $\overline{\text { Coefficients }}$ & t statistics & Response to & $\overline{\text { Coefficients }}$ & t statistics \\
\hline L.h_lnMV & $0.968 * * *$ & 21.13 & L.h_lnMV & -0.004 & -0.16 \\
\hline L.h_EPS & -0.02 & -0.23 & L.h_EPS & $0.723 * * *$ & 6.85 \\
\hline L.h_lnTA & 0.155 & 1.61 & L.h_lnTA & 0.056 & 1.08 \\
\hline L.h_DAR & -0.229 & -0.72 & L.h_DAR & -0.273 & -1.21 \\
\hline L.h_ROE & 0.377 & 1.37 & L.h_ROE & $1.876 * * *$ & 7.86 \\
\hline L.h_lnMI & $0.050 * *$ & 2.45 & L.h_lnMI & 0.013 & 1.15 \\
\hline L2.h_lnMV & $-0.102 * * *$ & -3.63 & L2.h__lnMV & -0.003 & -0.20 \\
\hline L2.h_EPS & -0.036 & -1.01 & L2.h_EPS & -0.057 & -1.57 \\
\hline L2.h_lnTA & -0.019 & -0.28 & L2.h_lnTA & $-0.044 *$ & -1.68 \\
\hline L2.h_DAR & 0.018 & 0.16 & L2.h_DAR & 0.004 & 0.05 \\
\hline L2.h_ROE & -0.086 & -0.44 & L2.h_ROE & $-1.078 * * *$ & -4.86 \\
\hline L2.h_lnMI & 0 & -0.01 & L2.h_lnMI & 0.009 & 0.86 \\
\hline Response of: & h_lnTA & & Response of: & h_DAR & \\
\hline Response to & Coefficients & t statistics & Response to & Coefficients & t statistics \\
\hline L.h_lnMV & -0.003 & -0.11 & L.h_lnMV & -0.004 & -0.35 \\
\hline L.h_EPS & 0.033 & 0.66 & L.h_EPS & $0.036^{*}$ & 1.88 \\
\hline L.h_lnTA & $0.845 * * *$ & 11.49 & L.h_lnTA & -0.008 & -0.32 \\
\hline L.h_DAR & 0.015 & 0.08 & L.h_DAR & $0.824 * * *$ & 12.03 \\
\hline L.h_ROE & 0.058 & 0.32 & L.h_ROE & 0.051 & 0.64 \\
\hline L.h_lnMI & 0.015 & 0.96 & L.h_lnMI & 0.006 & 1.11 \\
\hline L2.h_lnMV & -0.009 & -0.63 & L2.h_lnMV & -0.004 & -0.66 \\
\hline L2.h_EPS & -0.008 & -0.44 & L2.h_EPS & 0.01 & 1.28 \\
\hline L2.h_lnTA & 0.029 & 0.72 & L2.h_lnTA & 0.007 & 0.51 \\
\hline L2.h_DAR & 0.004 & 0.06 & L2.h_DAR & -0.004 & -0.14 \\
\hline L2.h_ROE & 0.001 & 0.01 & L2.h_ROE & $-0.124 * *$ & -2.38 \\
\hline L2.h_lnMI & 0.008 & 0.55 & L2.h_lnMI & 0.005 & 1.05 \\
\hline Response of: & h_ROE & & Response of: & h_lnMI & \\
\hline Response to & Coefficients & t statistics & Response to & Coefficients & t statistics \\
\hline L.h_lnMV & 0.004 & 0.35 & L.h_lnMV & $0.511 * * *$ & 2.66 \\
\hline L.h_EPS & 0.037 & 1.2 & L.h_EPS & 0.157 & 0.4 \\
\hline L.h_lnTA & -0.014 & -0.63 & L.h_lnTA & -0.298 & -0.83 \\
\hline L.h_DAR & -0.111 & -1.00 & L.h_DAR & -0.134 & -0.09 \\
\hline L.h_ROE & $0.854 * * *$ & 7.32 & L.h_ROE & -1.859 & -1.55 \\
\hline L.h_lnMI & -0.007 & -1.18 & L.h_lnMI & $-0.430 * * *$ & -4.29 \\
\hline L2.h_lnMV & -0.004 & -0.60 & L2.h_lnMV & $-0.548 * * *$ & -4.51 \\
\hline L2.h_EPS & $-0.043 * * *$ & -3.89 & L2.h_EPS & -0.123 & -0.71 \\
\hline L2.h_lnTA & 0.002 & 0.2 & L2.h_lnTA & $0.485 * *$ & 2.06 \\
\hline L2.h_DAR & 0.004 & 0.17 & L2.h_DAR & 0.052 & 0.09 \\
\hline L2.h_ROE & $-0.163 * *$ & -2.18 & L2.h_ROE & 0.782 & 0.83 \\
\hline L2.h_lnMI & -0.005 & -1.10 & L2.h_lnMI & $-0.641 * * *$ & -7.27 \\
\hline $\mathrm{N}$ & 1339 & & & & \\
\hline AIC & -8.569 & & & & \\
\hline BIC & -5.144 & & & & \\
\hline HQIC & -7.286 & & & & \\
\hline$* \mathrm{p}<0.1$ & $.05, * * * \mathrm{p}$ & & & & \\
\hline
\end{tabular}

As we can see from Table 10, before placard, the market value of the target listed companies is not only positively affected by its value of the first-order lag and negatively affected by its value of the second-order lag, but also significantly influenced by the main business income of the first-order lag, which shows great difference with Table 9 . With or without the placard, earnings per share, total assets, debt to asset ratio and profit margin on net assets variables all have relatively similar impacts on themselves and other variables. However, the main business income before the 
placard shows a more significant sensitivity to the previous market value of the company, while it does not show the similar performance after the placard. This shows that the influence of placard on the main business income is lagging behind, and the most sensitive response to the placard lies in the market value.

Therefore, for the target companies, the impact of the lag valuation on the current value has changed after placard, with the positive impact of the first-order lag value and negative impact of the second-order lag value before placard changing into the positive influence of these two lag period after placard. However, the positive impact of the first-order lag after placard is smaller than that before placard, which indicates that placard has weakened the target company's reliance on its previous market value. Simultaneously, the valuation of the target company is closely related to the company size and risk after placard, while the valuation is only closely associated with the company size before placard. In addition, the change in company size after placard is lagging behind, and the sensitivity of company profitability, size and risk to placard is not as good as the company valuation.

\subsection{Impulse Response Function Analysis}

The impulse response function describes the impact of unit random disturbance on other variables, which intuitively reflects the dynamic interactions, effects and the implied time lag relationship between variables.

Firstly, the result of impulse response function of PVAR-A(2) model is shown in Figure 1, with 95\% confidence interval. Based on the GMM estimation of PVAR-A(2) model, the paper will focus on the impact of the other five variables on the impulse response of the market value.

The market value increases in response of an earnings per share shock, as shown in Figure 1(IRF of EPS to lnMV). The 95\% confidence interval is above 0 at this point, which indicates the earnings per share of the company has a significant impact on its market value in the first period after placard. However, the effect is apparently weakened in the second period, and as time passes by, the impulse effect becomes smaller and smaller.

As shown in Figure 1(IRF of $\operatorname{lnTA}$ to $\operatorname{lnMV}$ ), the 95\% confidence interval is above 0 during the first five periods, which illustrates the market value increases in response of a total assets shock after placard, and the positive impact is significant at least in five periods. However, the market value will not be significantly affected by a debt to asset ratio shock in the first six periods, as shown in Figure 1(IRF of DAR to lnMV).

The market value increases in response of a profit margin on net assets shock, as shown in in Figure 1(IRF of ROE to lnMV), which is generally similar with earnings per share, but in the first period, the impulse effect of profit margin on net assets is smaller than the earnings per share in the first period.

The impulse effect of the main business income on the market value of the company shares a great difference from other variables above. At first, the main business income does not perform positive impact on the market value until the second period. However, the impact quickly decays in the third period and remains unapparent in the following three periods.

Secondly, the result of impulse response function of PVAR-B(2) model is shown in Figure 2, with 95\% confidence interval. The paper will also focus on the impact of the other five variables on the impulse response of the market value.

As shown in Figure 2(IRF of EPS to lnMV), the market value increases in response of an earnings per share shock in the first period before placard. However, the positive impact is no longer significant since the third period, which is similar with the performance after the target companies are placarded.

Figure 2(IRF of $\operatorname{lnTA}$ to $\operatorname{lnMV}$ ) shows that the impulse effect of total assets on the market value only performs positively in the first period, and the effect dramatically decays in the following periods, which is quite different 


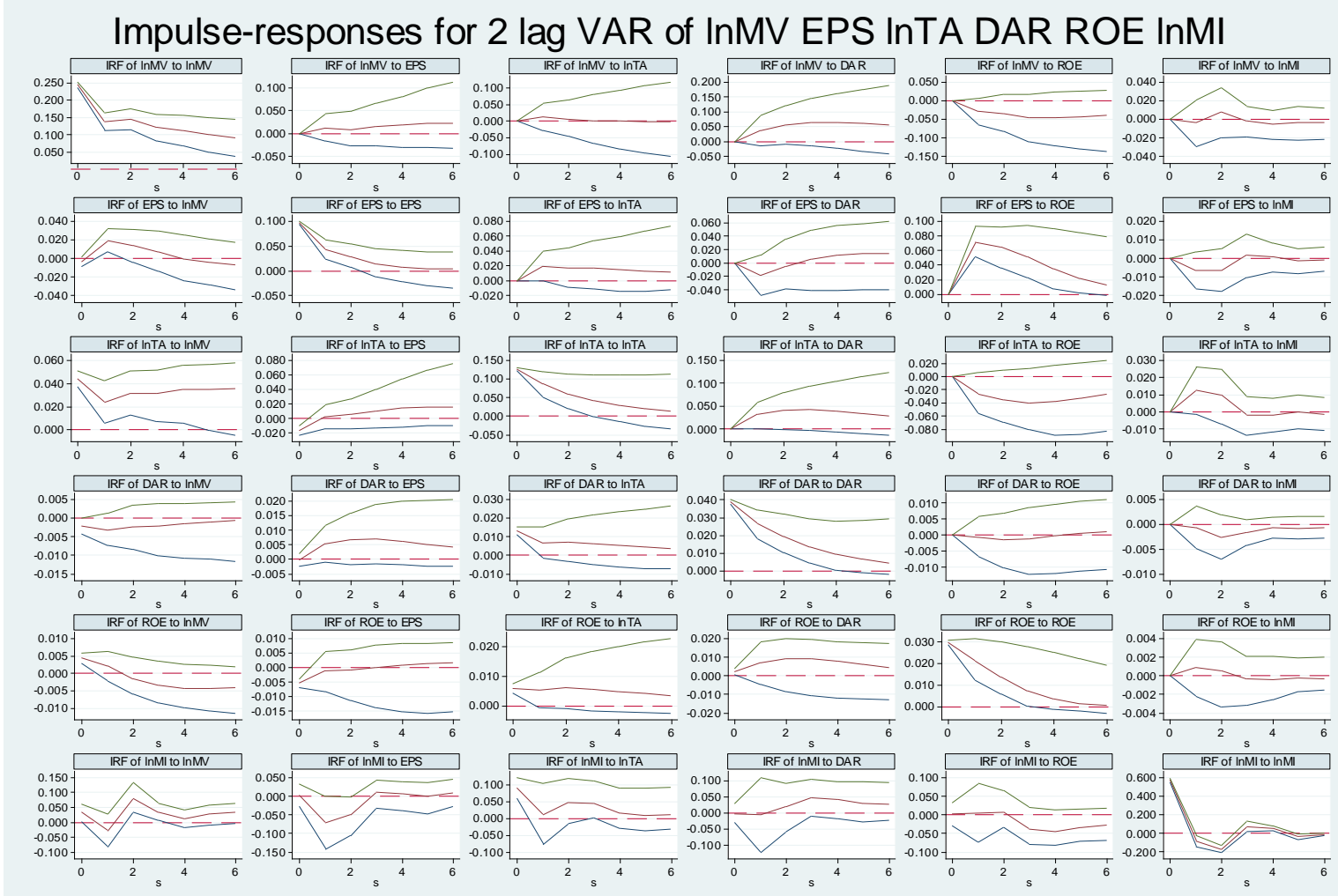

Errors are $5 \%$ on each side generated by Monte-Carlo with 1000 reps

Figure 1. Impulse responses for PVAR-A(2) model

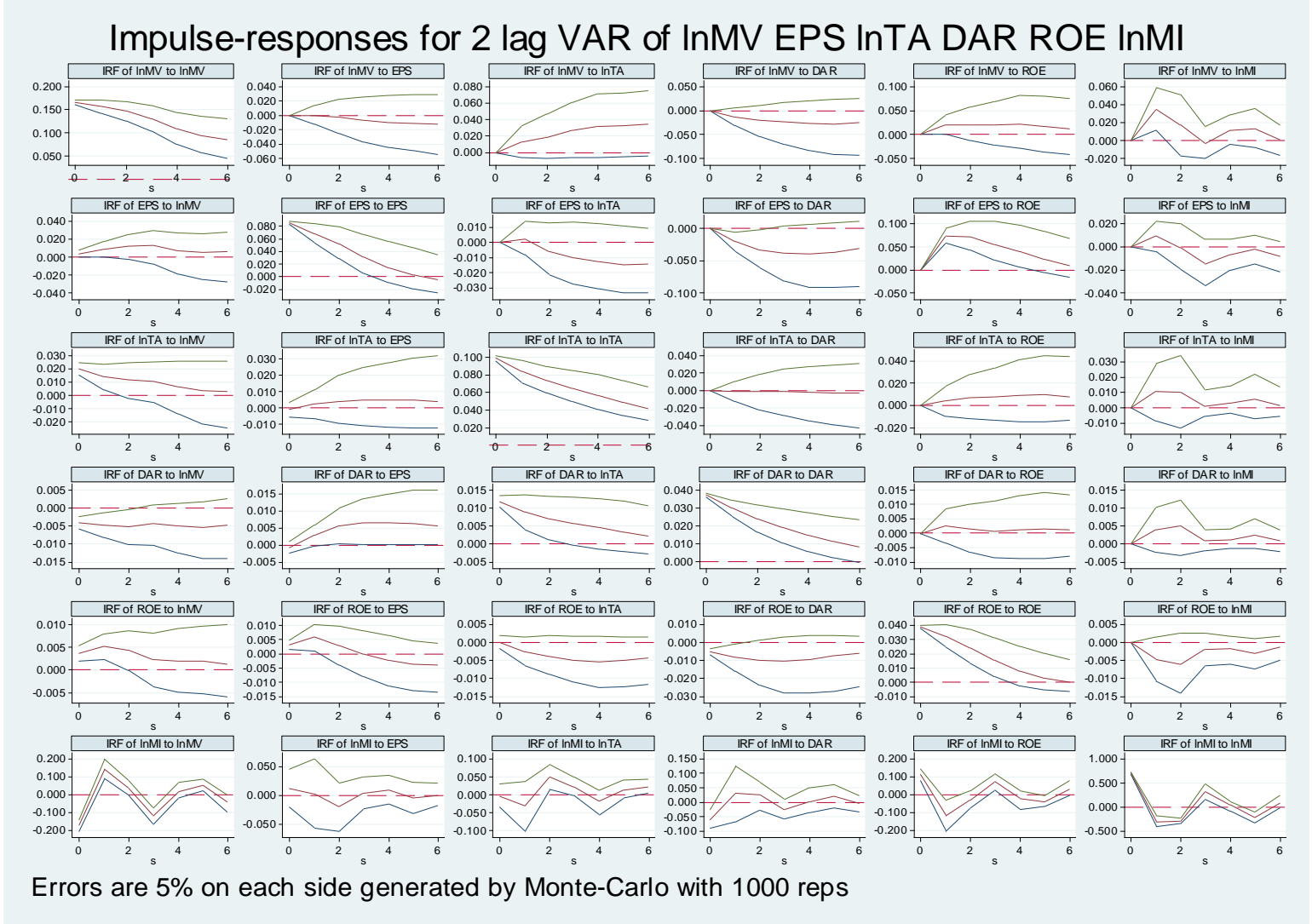

Figure 2. Impulse responses for PVAR-B(2) model 


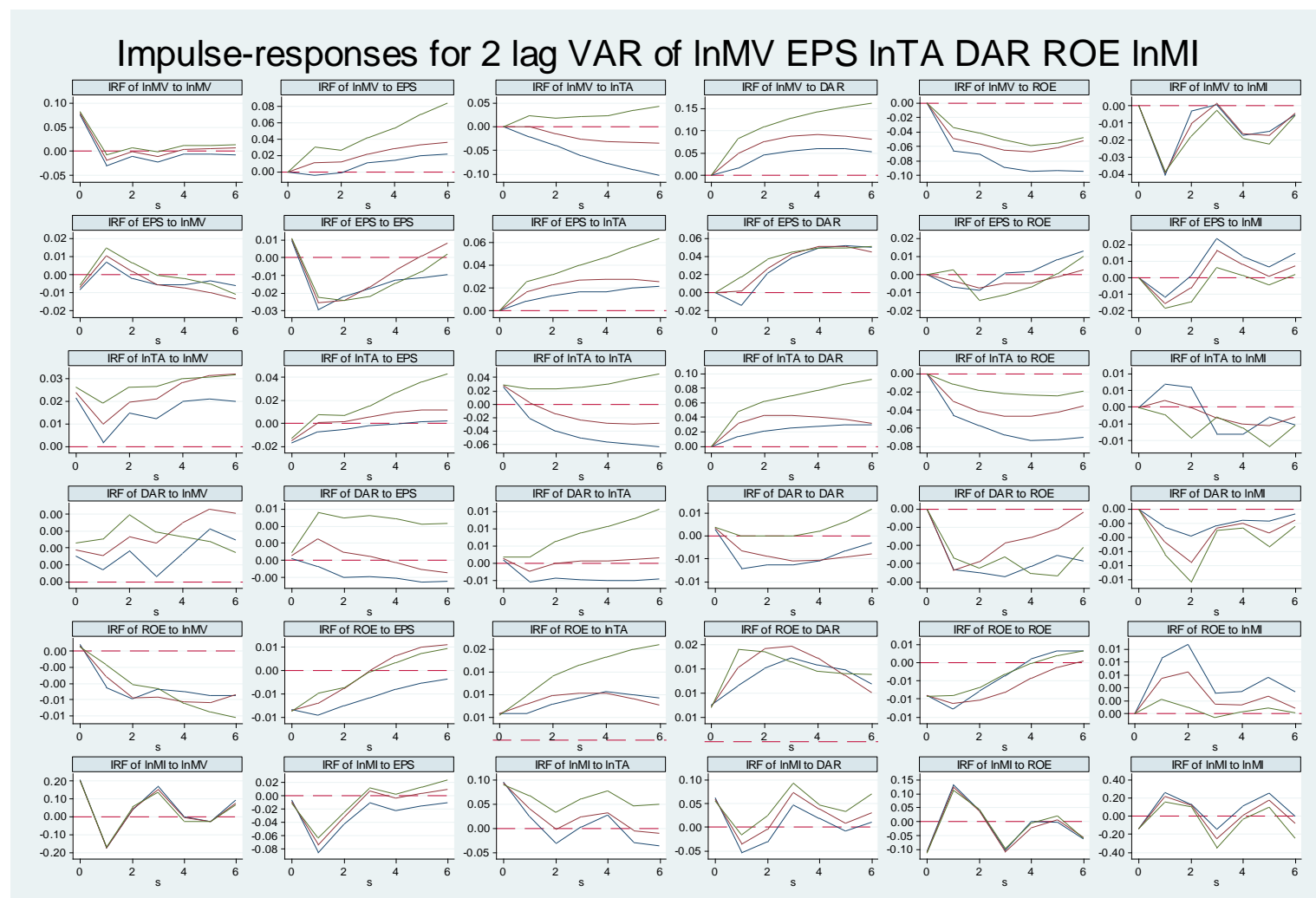

Errors are $5 \%$ on each side generated by Monte-Carlo with 1000 reps

Figure 3. Difference in impulse responses for PVAR-A(2) model and PVAR-B(2)(after placard-before placard)

from the performance of total assets after placard. However, the market value will not be significantly affected by a debt to asset ratio shock in the first six periods, as shown in Figure 2(IRF of DAR to lnMV), which share some resemblances with the performance of debt to asset ratio after placard.

As shown in Figure 2(IRF of ROE to lnMV), the market value increases in response of a profit margin on net assets shock, and the positive impact lasts at least two periods, but disappears since the third period, which is the same as the performance of profit margin on net assets after placard.

Like the impulse response function of PVAR-A(2) model, the impulse effect of the main business income on the market value of the company shares a great difference from other four variables. As shown in Figure 2(IRF of lnMI to lnMV), the market value only reacts positively to a main business income shock in the second period.

In addition, compared Figure 1 with Figure 2, the market value of the company shows a rising trend in the short term after placard, with the earnings per share rising, the total assets increasing, the debt to assets ratio remaining basically unchanged, the profit margin on net assets temporarily decreasing, and the main business income remaining stable. However, the decline in the profit margin on net assets is not as large as the increase in earnings per share. Therefore, it indicates that the valuation of the company increases after placard, accompanied with profitability strengthened, company size expanding and company risk remaining stable. It seems that barbarians at the gate bring the motivation for the target companies in the short term.

To confirm the change of company performance and valuation after the company is placarded, the paper make the differences between the impulse responses for the PVAR-A(2) model and PVAR-B(2)model, as shown in Figure 3.

As shown in Figure 3(IRF of EPS to lnMV), the confidence interval is above 0 in the first period, while the lower bound at $95 \%$ confidence breaks the 0 line, which indicates that the difference between two groups is only significant in the first period. Therefore, the sample group shows a stronger sensitivity of changes in the market value of the company after placard than that before placard, which is consistent with the results of Figure 1 and Figure 2.

The lower bound at $95 \%$ confidence is above 0 in the first six periods, which represents the difference between two sample groups is significant during first six periods, as shown in Figure 3(IRF of $\operatorname{lnTA}$ to $\operatorname{lnMV}$ ). Therefore, the market value of the company has an increased sensitivity to a total assets shock after placard, which is in line with the previous analysis of Figure 1 and Figure 2. 
As shown in Figure 3(IRF of DAR to lnMV), although the difference between two sample groups show a positive effect, it can be seen from the vertical axis that the difference is very small. Meanwhile, there is no significant difference in the response of market value to a profit margin on net assets shock, as shown in Figure 3(IRF of ROE to lnMV).

In Figure 3(IRF of lnMI to lnMV), the difference between two sample groups is significant only in the second and third periods, with the lower bound at $95 \%$ confidence above 0 , indicating that the market value of the company has an increased sensitivity in response of a main business income shock after placard, which is different from what we have concluded before.

It comes to a conclusion that the company is more sensitive to the impact of changes in its performance as a whole after placard. As shown in Figure 3(IRF of lnMV to lnMV), the market value of company behaves sensitively in response of its own shock, but the sensitivity soon declines, indicating that the market value has some regulating impact on itself. Therefore, in the long run, the influence brought by placard on the company will be adjusted to a steady state on the basis of the short-term impact.

\subsection{Variance Decomposition Analysis of Prediction Error}

By variance decomposition of prediction error, the paper examines how much the change in one variable contributes to the fluctuation of its own or other variables. Since the interaction between the variables is still weak in the short term, the paper chooses 20 periods when analyzing the variance decomposition. Considering the limitation in space, the article takes the results of the fourth, eighth, twelfth, sixteenth and twentieth periods as examples, which are shown in Table 11 and Table 12.

Table 11. Variance decomposition results of PVAR-A(2) model

\begin{tabular}{|c|c|c|c|c|c|c|c|}
\hline variable & $\mathrm{s}$ & $\operatorname{lnMV}$ & EPS & $\operatorname{lnTA}$ & DAR & ROE & $\operatorname{lnMI}$ \\
\hline $\operatorname{lnMV}$ & 4.000 & 0.894 & 0.004 & 0.001 & 0.068 & 0.033 & 0.001 \\
\hline EPS & & 024 & 464 & 037 & .015 & 0.457 & 0.003 \\
\hline $\operatorname{lnTA}$ & 4.000 & 107 & 009 & 687 & .107 & 0.084 & 0.006 \\
\hline DAR & 4.000 & .008 & 0.037 & 0.094 & 0.858 & 0.001 & 0.003 \\
\hline ROE & .000 & 018 & 0.015 & .063 & 0.114 & 0.788 & 0.001 \\
\hline $\operatorname{lnMI}$ & & & 019 & & 0.007 & .004 & 916 \\
\hline $\operatorname{lnMV}$ & 000 & 809 & 0.013 & .001 & 0.118 & 0.059 & 0.001 \\
\hline & 8.000 & 025 & 0.413 & .054 & 0.037 & 0.468 & 0.003 \\
\hline $\operatorname{lnTA}$ & 000 & & 0.023 & & & 0.127 & 0.005 \\
\hline DAR & 00 & & & & & & 003 \\
\hline & 000 & & 0.017 & & & & 001 \\
\hline & 000 & & 0.019 & & & 0.014 & 0.891 \\
\hline $\operatorname{lnMV}$ & .000 & 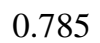 & 0.019 & & 0. & 0.062 & 0.001 \\
\hline & .000 & & 0.406 & 58 & & 0.460 & 0.003 \\
\hline $\operatorname{lnTA}$ & .000 & 0.208 & 0.029 & 0.475 & 0.158 & 0.125 & 0.004 \\
\hline & 0 & & 0.0 & & & & 0.003 \\
\hline ROE & .000 & 55 & 0.018 & & 0. & 0.685 & 0.001 \\
\hline & .000 & 0.036 & 0.020 & 0.030 & & 0.015 & 0.881 \\
\hline $\operatorname{lnMV}$ & .000 & & 0.021 & & & 0.062 & 0.001 \\
\hline & & 3 & 0. & & & & 0.003 \\
\hline & .000 & 0.228 & 0.031 & 52 & 0.162 & 0.123 & 0.004 \\
\hline DAR & .000 & 0.008 & 0.062 & 0.108 & & 0.003 & 0.003 \\
\hline & & & & & & & 0.001 \\
\hline & & & & & & 0.016 & 0876 \\
\hline $\operatorname{lnMV}$ & .000 & 0.772 & 0.022 & 0.001 & 0.143 & 0.061 & 0.001 \\
\hline & 20.000 & & 0.4 & 59 & 0.041 & 0.458 & 0.003 \\
\hline & & & & & & & 0.004 \\
\hline & & & & & & & 0003 \\
\hline ROE & 20.000 & 0.060 & 0.018 & 0.086 & 0.154 & 0.681 & 0.001 \\
\hline 1 & 20.000 & 0.041 & 0.020 & 0.030 & 0.019 & 0.016 & 0.874 \\
\hline
\end{tabular}

As can be seen from Table 11, for the market value of company, most of the variance in its prediction error comes from itself, but the proportion decreases as time passes by, with a more and more slowly speed over the same time interval. Among the other four variables, the contribution of debt to asset ratio to the variance of the market value shows a trend of gradual expansion. 
Table 12. Variance decomposition results of PVAR-B(2) model

\begin{tabular}{cccccccc}
\hline variable & $\mathrm{s}$ & lnMV & EPS & lnTA & DAR & ROE & lnMI \\
\hline lnMV & 4.000 & 0.946 & 0.001 & 0.013 & 0.012 & 0.013 & 0.016 \\
EPS & 4.000 & 0.012 & 0.471 & 0.004 & 0.088 & 0.415 & 0.009 \\
lnTA & 4.000 & 0.031 & 0.002 & 0.956 & 0.000 & 0.004 & 0.008 \\
DAR & 4.000 & 0.023 & 0.022 & 0.080 & 0.861 & 0.003 & 0.011 \\
ROE & 4.000 & 0.017 & 0.014 & 0.012 & 0.076 & 0.866 & 0.015 \\
lnMI & 4.000 & 0.073 & 0.001 & 0.004 & 0.007 & 0.037 & 0.878 \\
lnMV & 8.000 & 0.896 & 0.004 & 0.041 & 0.028 & 0.017 & 0.014 \\
EPS & 8.000 & 0.013 & 0.387 & 0.021 & 0.180 & 0.388 & 0.011 \\
lnTA & 8.000 & 0.025 & 0.003 & 0.953 & 0.001 & 0.011 & 0.007 \\
DAR & 8.000 & 0.040 & 0.048 & 0.076 & 0.820 & 0.004 & 0.011 \\
ROE & 8.000 & 0.018 & 0.023 & 0.030 & 0.114 & 0.798 & 0.017 \\
lnMI & 8.000 & 0.074 & 0.001 & 0.005 & 0.007 & 0.037 & 0.877 \\
lnMV & 12.000 & 0.864 & 0.007 & 0.067 & 0.034 & 0.016 & 0.013 \\
EPS & 12.000 & 0.015 & 0.380 & 0.027 & 0.192 & 0.375 & 0.011 \\
lnTA & 12.000 & 0.023 & 0.004 & 0.952 & 0.002 & 0.013 & 0.007 \\
DAR & 12.000 & 0.052 & 0.055 & 0.074 & 0.804 & 0.004 & 0.011 \\
ROE & 12.000 & 0.019 & 0.029 & 0.034 & 0.115 & 0.786 & 0.017 \\
lnMI & 12.000 & 0.074 & 0.001 & 0.005 & 0.007 & 0.037 & 0.876 \\
lnMV & 16.000 & 0.846 & 0.007 & 0.083 & 0.036 & 0.016 & 0.012 \\
EPS & 16.000 & 0.017 & 0.380 & 0.027 & 0.192 & 0.373 & 0.011 \\
lnTA & 16.000 & 0.023 & 0.004 & 0.951 & 0.002 & 0.013 & 0.007 \\
DAR & 16.000 & 0.057 & 0.056 & 0.074 & 0.798 & 0.004 & 0.011 \\
ROE & 16.000 & 0.020 & 0.029 & 0.034 & 0.115 & 0.784 & 0.017 \\
lnMI & 16.000 & 0.074 & 0.001 & 0.005 & 0.007 & 0.037 & 0.876 \\
lnMV & 20.000 & 0.836 & 0.007 & 0.092 & 0.036 & 0.016 & 0.012 \\
EPS & 20.000 & 0.018 & 0.379 & 0.027 & 0.192 & 0.373 & 0.011 \\
lnTA & 20.000 & 0.023 & 0.004 & 0.951 & 0.002 & 0.013 & 0.007 \\
DAR & 20.000 & 0.059 & 0.056 & 0.075 & 0.795 & 0.004 & 0.011 \\
ROE & 20.000 & 0.021 & 0.029 & 0.034 & 0.115 & 0.784 & 0.017 \\
lnMI & 20.000 & 0.074 & 0.001 & 0.005 & 0.007 & 0.037 & 0.876 \\
\hline
\end{tabular}

As we can see from Table 12, for the samples before placard, most of the variance of the market value in its prediction error also comes from itself, but the proportion also decreases gradually over time, with a more and more slowly speed over the same time interval. Besides, during the same term, the market value contributes apparently more to its variance of prediction error before placard than that after placard. Among the other four variables, the contribution of total assets to the variance of the market value shows a trend of gradual expansion, which is different from the results of PVAR-A(2) model.

Compared Table 11 with Table 12, it seems that the volatility of the market value of company has less dependence on itself after placard than before, and its fluctuation comes more from other variables. In addition, the performance of earnings per share, total assets, debt to asset ratio, profit margin on net assets and the main business income shares resemblances with the market value of company, which, to some extent, indicates that placard reduce the company's own reliance on valuation, profitability, size and risk. In this way, it is beneficial for the target company to fully coordinate the development, optimize the resources and structure of the company, so as to enhance the market value and gain more favorable position in the competition.

\section{Conclusions}

Based on the placard events happened in the Chinese secondary securities market from 2011 to 2015 , the paper establishes an improved PVAR model to carry out a deep analysis on the factors that affect the company performance and valuation, and then obtains comparably accurate results of placard effect on the target listed companies.

First, the changes in performance and valuation of the company are different after placard, compared with that before placard. For the target companies, the impact of the lag valuation on the current value has changed after placard, with the positive impact of the first-order lag value and negative impact of the second-order lag value before placard changing into the positive influence of these two lag period after placard. However, the positive impact of the first-order lag after placard is smaller than that before placard, which indicates that placard has weakened the target company's reliance on its previous market value. Simultaneously, the valuation of the target company is closely related to the 
company size and risk after placard, while the valuation is only closely associated with the company size before placard. In addition, the change in company size after placard is lagging behind, and the sensitivity of company profitability, size and risk to placard is not as good as the company valuation.

Second, there are some changes existing in the sensitivity to impulse and the value of variables after placard. The results of impulse response function indicate that the valuation of the company increases after placard, accompanied with profitability strengthened, company size expanding and company risk remaining stable. It seems that barbarians at the gate bring the motivation for the target companies in the short term. In addition, the company is more sensitive to the impact of changes in its performance as a whole after placard. Meanwhile, the market value of company behaves sensitively in response of its own shock after placard, but the sensitivity soon declines, indicating that the market value has some regulating impact on itself. Therefore, in the long run, the influence brought by placard on the company will be adjusted to a steady state on the basis of the short-term impact.

Third, the interrelationships among financial variables are closer because of the placard impulse than before, and a relatively stable state can be reached after a long period of time, which is more stable than that before placard. Therefore, placard reduce the company's own reliance on valuation, profitability, size and risk. In this way, it is beneficial for the target company to fully coordinate the development.

Placard is a good signal for those target enterprises on the whole, which brings a nice momentum for the enterprises on the valuation, profitability, size and risk in the short term. After placard, the financial variables of the company are more sensitive to the shocks, and meanwhile the dependence on other variables is increased, which assists the company to restore the original balance by controlling other variables in the face of the shocks. However, the company cannot passively face the shocks arising from placard and let it develop freely. Instead, the company should adopt a positive strategy to maintain the long-term management, with the purpose of passing a good signal of the company growth to the market and specifying the direction of future corporate governance and development. As for the major shareholders and ordinary investors, the target stocks also conveys a good and valuable signal on the whole. From this point of view, "barbarians at the gate" bring the motivation rather than chaos.

\section{References}

Berdiev, A. N., \& Saunoris, J. W. (2016). Financial development and the shadow economy: A panel VAR analysis. Economic Modelling, 57, 197-207. https://dx.doi.org/10.1016/j.econmod.2016.03.028

Chen, Y. (2016). A case study on economic consequences of the listed companies which have been placarded on the basis of different motivations. Shenyang University of Technology.

Gugler, M., \& Yurtoglu. (2003). The effects of mergers: an international comparison. International Journal of Industrial Organization, 21(5), 625-653. https://dx.doi.org/10.1016/S0167-7187(02)00107-8

He, J., \& Xu, L. (2012). The path and influence of industrial capital infiltrating into financial capital: a study based on the placard events of capital market. Financial Research, (02), 81-90.

Kumar, M. S. (1985). Growth, Acquisition Activity and Firm Size: Evidence from the United Kingdom. Journal of Industrial Economics, 33(3), 327-338. https://dx.doi.org/10.2307/2098540

Lei, H., Shao, H., \& Li, A. (2010).The effect of M\&A of low-carbon listed companies on the labor demand: based on the empirical analysis of dynamic panel data. System Engineering, (12), 69-74.

Love, I., \& Zicchino, L. (2006). Financial development and dynamic investment behavior: Evidence from panel VAR. Quarterly Review of Economics \& Finance, 46(2), 190-210. https://dx.doi.org/10.1016/j.qref.2005.11.007

Luo, C. (2016). R\&D intensity, payment gap and company performance: a simultaneous equation model based on panel data. Accounting Monthly, (08), 38-43.

Lv, P. (2014). Research on market reaction and its influencing factors of placard carried out by the shareholders in listed companies. Nanjing University.

Pang, J. (2014). An empirical study on the shareholding-change behavior of large shareholders and corporate performance. Southwestern University of Finance and Economics.

Rao, N. R., Salaber, J., \& Cao, T. H. (2016). Long-term performance of mergers and acquisitions in ASEAN countries. Research in International Business \& Finance, 36, 373-387. https://dx.doi.org/10.1016/j.ribaf.2015.09.024

Sun, X. (2011). An empirical study on short-term influence of large shareholders' stock-increase behavior on stock prices in China. Dongbei University of Finance and Economics.

Wu, J. (2012). M\&A performance analysis of Chinese listed pharmaceutical companies based on the panel data. Inner Mongolia University. 
Yang, Y. (2013). The stockholding-increase behavior of senior executives in listed companies: a study of behavioral motivation and market effect. Southwestern University of Finance and Economics.

Zuo, W. (2014). Research on the factors that affect the executive compensation based on panel data. University of Science and Technology Liaoning.

\section{Copyrights}

Copyright for this article is retained by the author(s), with first publication rights granted to the journal.

This is an open-access article distributed under the terms and conditions of the Creative Commons Attribution license which permits unrestricted use, distribution, and reproduction in any medium, provided the original work is properly cited. 